\title{
New insights into IDO biology in bacterial and viral infections
}

\section{Susanne V. Schmidt and Joachim L. Schultze*}

Genomics and Immunoregulation, LIMES-Institute, University of Bonn, Bonn, Germany

\section{Edited by:}

Ursula Grohmann, University of

Perugia, Italy

\section{Reviewed by:}

Dietmar Fuchs, Innsbruck Medical

University, Austria

Masahide Tone, Cedars-Sinai Medical

Center, USA

Paolo Puccetti, University of Perugia, Italy

\section{*Correspondence:}

Joachim L. Schultze, Genomics and Immunoregulation, LIMES-Institute, University of Bonn, Carl-Troll-Street

31, Bonn 53115, Germany

e-mail: j.schultze@uni-bonn.de
Initially, indoleamine-2,3-dioxygenase (IDO) has been introduced as a bactericidal effector mechanism and has been linked to T-cell immunosuppression and tolerance. In recent years, evidence has been accumulated that IDO also plays an important role during viral infections including HIV, influenza, and hepatitis B and C. Moreover, novel aspects about the role of IDO in bacterial infections and sepsis have been revealed. Here, we review these recent findings highlighting the central role of IDO and tryptophan metabolism in many major human infections. Moreover, we also shed light on issues concerning humanspecific and mouse-specific host-pathogen interactions that need to be considered when studying the biology of IDO in the context of infections.

Keywords: IDO, viral infection, bacterial infection, depressive disorders, kyn metabolites

\section{INTRODUCTION}

Indoleamine-2,3-dioxygenase (IDO) is an intracellular, nonsecreted enzyme, which catabolizes the production of kynurenine (Kyn) derivates from tryptophan (Trp). Anti-proliferative features of IDO on bacteria, protozoa, and tumor cells have been first described in 1984 by Pfefferkorn (1) as well as Taylor and Feng (2). Induction of IDO in cells of the immune system by IFN $\gamma$ was introduced for the first time in the late 1980s $(3,4)$. Today, IDO is thought to be part of a fast local immune regulatory mechanism called "metabolic immune regulation" to protect the host from over-reactive immune reactions via induction of systemic immune tolerance [reviewed elsewhere (5)]. It participates in a broad spectrum of immune responses during chronic infections, immune-escape of cancer cells, tissue inflammation, transplantation, and maternal tolerance toward the fetus and autoimmunity (6). Interestingly, accumulating evidence also connects enhanced Trp metabolism to mental disorders based on serotonin starvation.

Exogenous inflammatory stimuli induce the expression of IDO in antigen-presenting cells (APCs), such as dendritic cells (DC) (7), macrophages (4), and B-cells. Gene expression of IDO was found to be regulated by interferon- $\alpha$ (IFN $\alpha$ ) and interferon $\gamma(\operatorname{IFN} \gamma)$ and also TNF $\alpha$ and prostaglandins $(8,9)$. As mode of action for IDO, $\mathrm{O}_{2}^{-}$-radical scavenging $(2,10)$ and later suppression of T-cell responses $(11,12)$ were discussed. Since many microbial organisms rely on the essential amino acid Trp, its degradation by IDO-expressing cells of the innate immune system was favored as the major IDO-mediated mechanism against infections (13). In infectious disease states, IDO has been shown to exert pleiotropic effects, even with opposing outcomes. On the one hand, IDO directly suppresses the replication of certain parasites and bacteria $(1,14-16)$, or at least prevents viral spread (17-20), on the other hand, it also acts on host cells to suppress immune reactions thereby promoting infectious diseases $(21,22)$.
Besides Trp depletion, production of Trp metabolites with bactericidal activity, like Kyn, were identified in human macrophages upon infection with diverse bacteria species as another defense mechanism mediated by IDO (23). IFN $\gamma$ induced Trp degradation leading to anti-toxoplasmosis activity in infected human fibroblasts was first described by Pfefferkorn in 1984 (1). Only a few years later, several studies linked this effect to enhanced IDO activity against pathogens like Toxoplasma gondii, certain Chlamydia psittaci strains and Leishmania donovani (14-16). In these initial studies, IDO-expressing immune cells were described as macrophages. A contribution of IDO in containment of viral infections was suggested by in vitro experiments demonstrating that the inhibition of human cytomegalovirus (CMV) replication was induced by IFN $\gamma$ and IFN $\beta$ (18). This virostatic effect could be reverted by addition of exogenous Trp indicating an involvement of IDO $(17,19,20)$. Interestingly, the activity of inducible nitric oxide synthetase (iNOS) was suggested to be able to substitute for the IDO-mediated anti-viral mechanism $(18,24)$. Since then, it was demonstrated that other viruses, such as herpes simplex virus type 2 (HSV-2) (17), measles virus (19), and vaccinia virus (20), are sensible to IDO-induced Trp depletion.

Apparently, pathogens are able to highjack the immunosuppressive effects of IDO and make use of them to facilitate their own life cycle. For instance, uropathogenic Escherichia coli (UPEC) induce IDO in epithelial cells of the urinary tract and in polymorphonuclear leukocytes (21). The dampened immune response upon IDO induction enables a successful colonization of urinary epithelium by UPEC. In addition, viruses like human immunodeficiency virus 1 (HIV) use the immunosuppressive activity of IDO to drive HIV infection into the chronic phase (25). In the following chapters, we will focus on new insights into the role of IDO and Kyn derivates in major viral and bacterial infections in mice and men. 


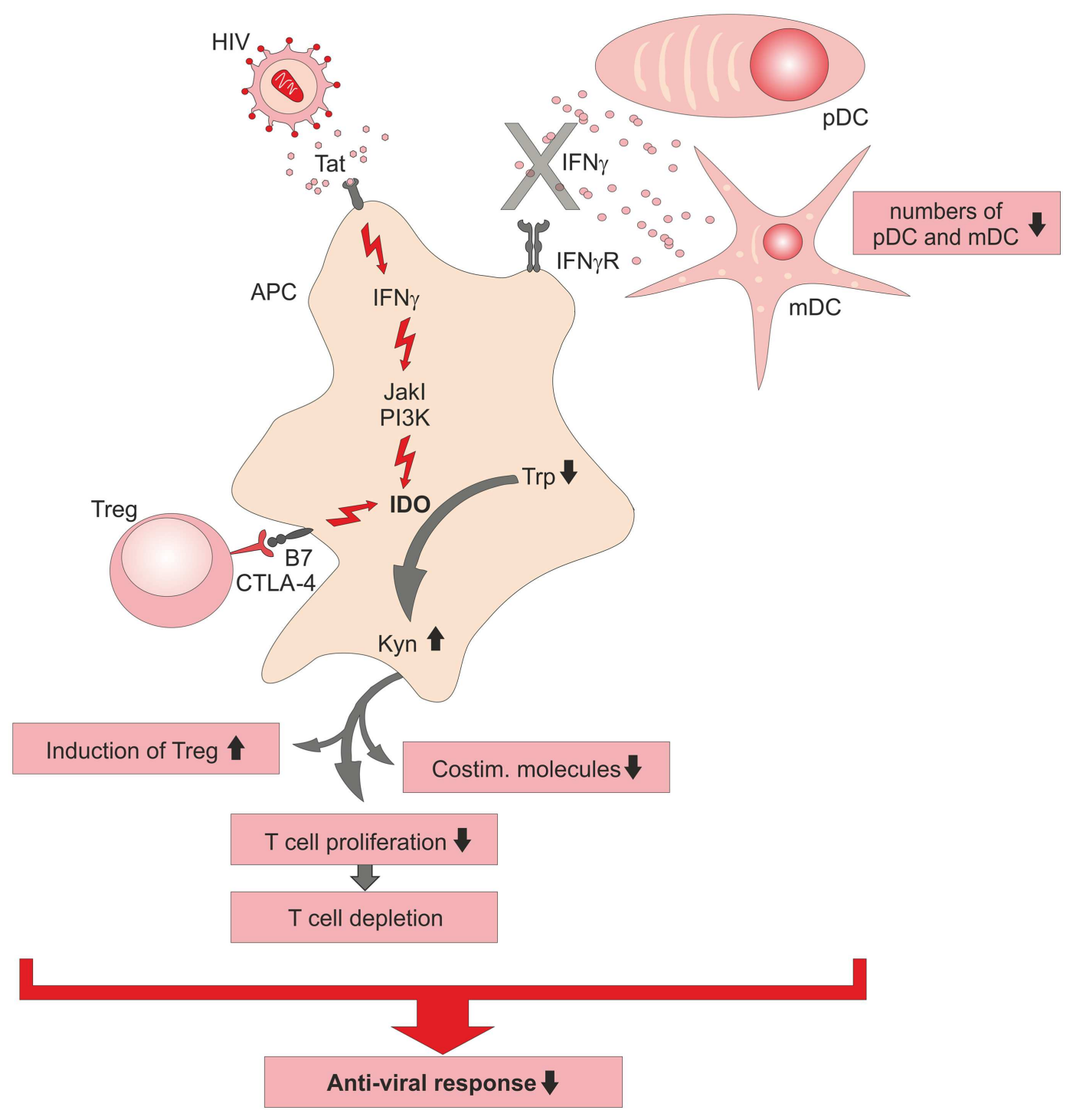

FIGURE 1 | Schematic summary of immunosuppressive functions of indoleamine-2,3-dioxygenase (IDO) during HIV infection. Direct induction of IDO in antigen-presenting cells (APC) by viral Tat protein is established via an intracellular signaling cascade including kinases (Jakl, PI3K) or CTLA-4-B7 interaction on regulatory $T$ (Treg)-cells with B7 co-receptor on the APC, which leads in consequence to a breakdown of tryptophan (Trp) into kynurenine (Kyn). Diminished anti-viral immune responses during chronic HIV infection is caused by an impaired T-cell response, the lack of potent IFN $\gamma$ secreting DC, and the induction of immunosuppressive IDO+ APC. pDC, plasmacytoid DC; $\mathrm{mDC}$, myeloid DC.

\section{ROLE OF IDO IN VIRAL INFECTIONS ROLE OF IDO IN HIV INFECTION}

Infection with HIV causes a severe impairment of T-cell responses by loss of proliferative capacity of T-cells accompanied by a depletion of functionally competent $\mathrm{CD} 4{ }^{+} \mathrm{T}$ helper cells and by induction of regulatory T-cells (Treg) during the chronic phase of HIV infection (Figure 1). The exact T-cell impairing mechanism is still not completely understood, but inhibitory molecules on $\mathrm{T}$ cell function have been investigated intensely [reviewed elsewhere (26)]. Elevated serum levels of IFN $\gamma(27,28)$ and Kyn (29) in HIV patients pointed toward a participation of IDO in suppression of T-cell function, yet molecular mechanisms were unknown. Further support came from increased IDO mRNA levels measured in peripheral blood mononuclear cells (PBMCs) of HIV-infected patients (30). In vitro infection of PBMC led to the secretion of IFN $\alpha$ and IFN $\beta$ by plasmacytoid dendritic cells (pDC) (31). While both $\mathrm{CD}^{+}{ }^{+}$and $\mathrm{CD} 8^{+}$T-cells expressed the activation markers CD69 and CD38, they failed to proliferate and were insensitive to T-cell receptor stimulation, a status described as division arrest anergy (32). While $\mathrm{CD}^{+}{ }^{+} \mathrm{T}$-cells were arrested in G1/S phase, $\mathrm{CD}^{+}$T-cells downregulated the costimulatory receptor CD28. When the enzymatic activity of IDO was inhibited by 1-methyl tryptophan (1-MT), CD4 ${ }^{+}$and $\mathrm{CD}^{+}{ }^{+}$T-cells regained their ability to proliferate $(30,31)$. In monocyte-derived DC (moDC), the Nterminal domain of HIV-1 transactivator regulatory protein (Tat) induced IFN $\gamma$ and IDO expression and therefore further led to a 
suppression of T-cell proliferation. Here, 1-MT was also able to reconstitute T-cell proliferation (33). IDO expression was initially induced by Tat and followed by the induction of IFN $\gamma$ leading to a feed forward loop. Interestingly, IFN $\gamma$ signaling pathways leading to IDO expression could be blocked by JAKs and PI3K inhibitors but Tat-induced IDO expression could not be inhibited, suggesting a novel so far not characterized mechanism of IDO induction by Tat proteins in HIV infection (33).

In simian immunodeficiency virus (SIV)-infected macaques, treatment with a combination of antiretroviral therapy (ART) and 1-MT successfully diminished viral loads in plasma and lymph nodes and restored Trp levels but did not reduce Kyn (34). It is worth to mention that 1-MT alone was not able to restrain viremia in this animal model. Probably, IDO was only partially inhibited since reconstituted Trp levels were accompanied with elevated Kyn levels in sera of treated animals. Further, a compensatory counterregulatory mechanism for 1-MT was suggested due to increased IDO and TGF $\beta$ production in lymph nodes of treated animals. Decreased numbers of $\mathrm{CD} 4^{+} \mathrm{T}$-cells during the course of HIV infection are accompanied by a loss of type I IFN producing cells, like pDC $(35,36)$. One reason for the low pDC numbers might be their redistribution to peripheral lymph nodes, as observed in the acute phase of SIV-infected macaques (36). Also, numbers of myeloid DC ( $\mathrm{mDC}$ ) are diminished in blood of HIV patients during primary infection (37). Yet, little is known about IDO expression in HIV-infected mDC. To investigate, if $\mathrm{HIV}$ alters the function of infected $\mathrm{mDC}$, PBMC-derived $\mathrm{DC}$ were transfected with a HIV containing vector construct as a model system (38). This resulted in the induction of IDO in immature and matured DC, accompanied by increased levels of Kyn. In addition, elevated levels of TNF $\alpha$ and IFN $\gamma$ were secreted by these DC with mature DC secreting the highest amounts. Further, HIVtransduced mature DC induced only modest T-cell proliferation in mixed-lymphocyte reactions, which might be due to IDO activity depleting Trp, a necessary molecule for T-cell function. The addition of 1-MT restored the immunostimulatory capacity of these DC, suggesting a central role of IDO in the suppression induced by HIV-infected DC.

Another mechanism of IDO expression in APCs is mediated by regulatory T-cells (Treg) $(39,40)$. In HIV patients, an elevated enzymatic activity of IDO in APCs was associated with a reduced anti-viral T-cell response [reviewed elsewhere (41)], while depletion of Treg cells reconstituted anti-HIV immune responses (42). Similarly, in SIV-infected macaques, the expression of the Treg markers CTLA-4 and FoxP3 was increased in T-cells of mesenteric lymph nodes, spleen, and colon, organs with high viral load (43). Simultaneously, IDO expression in spleen and gut-associated lymphoid tissues was suggested to support immunological suppression in favor of viral replication. Therefore, therapeutic targeting of Treg in HIV patients thereby reducing IDO expression in APCs and subsequently immunosuppression seemed promising. However, when blocking CTLA-4 signaling in SIV-infected macaques, an unexpected increase in IDO expression and Kyn levels was observed (44). Moreover, even under conditions of increased Tcell activation due to loss of the regulatory CTLA-4 signaling, viral replication was still promoted. Increased IDO levels were suggested to be a consequence of viral replication. In another attempt to refine ART by combining CTLA-4-blockade and 1-MT treatment, severe side effects causing acute pancreatitis with massive lymphocyte infiltration into the pancreas and loss of Langerhans islets were induced (45). Moreover, all tested animals developed diabetes and hyperglycemic coma while SIV-specific responses were not observed. These results clearly illustrate that the reversal of immunosuppression by targeting CTLA- 4 in chronic viral infection is not a promising approach.

The influence of IDO expression on viral loads in mice infected with the retroviral leukemia virus LP-BM5 is controversially discussed. In an earlier study, higher numbers of pDC in IDO KO mice correlated with increased levels of type I IFN and reduced viral load (46). However, in a more recent study using the same model, IDO had no impact on disease progression (47). Viral loads of IDO KO mice were comparable to those of wild-type B6 mice and both IDO KO and WT mice showed decreased responsiveness to B-cell and T-cell mitogens. One might postulate that an important denominator of efficacy targeting IDO might simply be the time when IDO is induced during the course of the infection. Clearly, more work is necessary to determine the role of IDO in murine retroviral infections.

An interesting link between chronic inflammatory diseases and neurological disorders has been recently made with IDO being involved. Patients suffering from chronic inflammatory diseases show often signs of depressive mood behavior (Figure 2). In patients with chronic HIV infection, the elevated Trp catabolism maintained by IDO expression is associated with reduced levels of free serum $\operatorname{Trp}(48,49)$. This correlates with a reduction of serotonin (5-HT) and serotonin transporter (5-HTT) expression, as well as an accumulation of neurotoxic Trp metabolites (50). Especially, Kyn and quinolinic acid (QA) can be detected in cerebrospinal fluids of HIV patients and are linked to the development of neuropsychiatric disorders, as part of the Neuro-AIDS complex of symptoms (50). HIV-1 associated dementia (HAD) is correlated to IDO and Kyn induced by Tat of HIV-1 clade $B$ in human primary astrocytes (51) while Tat of HIV-1 clade $\mathrm{C}$ does not induce IDO activity in human primary astrocytes and is not associated with HAD. Further evidence for the role of Tat for IDO expression in the brain came from experiments injecting Tat protein intracerebroventricularly into different mice strains. Further, when injecting Tat, induction of IDO and several other pro-inflammatory cytokines in the brain was associated with reduced mobility and depressive-like behavior (52), demonstrating the important role of IDO in the pathophysiology of HIV infection. Blockade of IDO or upstream events of IDO induction in chronic infection might be a novel approach to treat chronic HIV infections.

\section{ROLE OF IDO IN INFLUENZA INFECTION}

So far, research of IDO function has focused mainly on murine influenza infection models. Infection with murine influenza virus PR8 has been shown to induce IDO expression in mouse lung tissue $(53,54)$ and lung-associated lymph nodes (54). IDO activity increased during influenza infection and peak expression correlated with increased lymphocyte numbers in the respiratory tract, albeit the study did not discriminate between T-cell and B-cell subpopulations (53). In another study, inhibition of IDO 


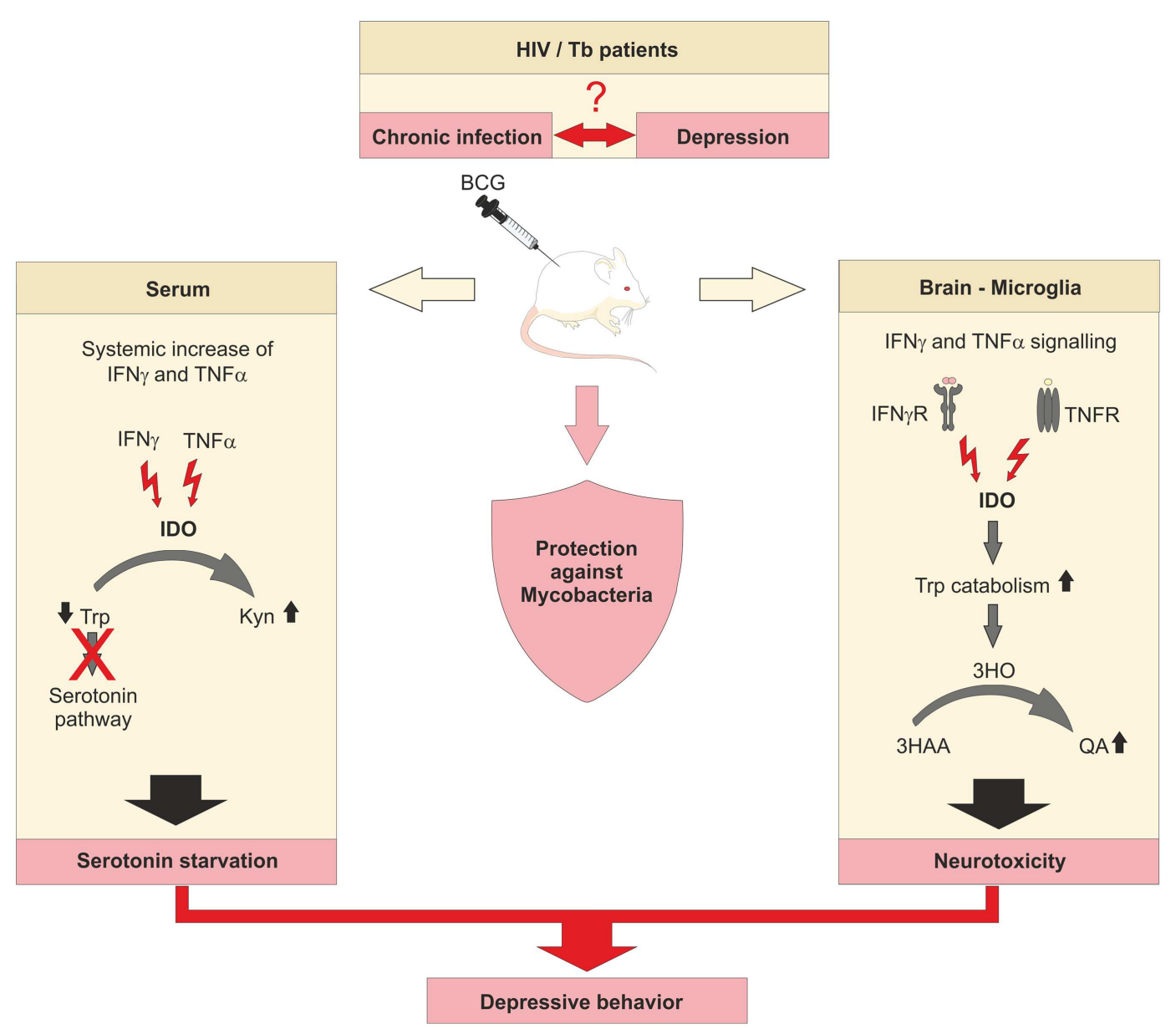

FIGURE 2 | IDO links chronic viral and bacterial infections to cases of depression. Underlying mechanisms of the connection between chronic infection with viruses or bacteria and the onset of mental disorders in men are unknown. Insufficient levels of serotonin in chronically infected and depressive patients are thought to be the consequence of constitutively elevated levels of IDO. Murine models of chronic infections are established to decipher the involvement of IDO in the development of depressive-like behavior. by 1-MT treatment in influenza-infected mice led to increased numbers of virus-specific memory $\mathrm{CD} 8^{+} \mathrm{T}$-cells and functionally activated effector $\mathrm{CD}^{+}{ }^{+} \mathrm{T}$-cells (55). In a follow-up study, 1MT-treatment improved memory $\mathrm{T}$-cell responses correlated with increased secretion of IFN $\gamma$ by $\mathrm{CD}^{+}{ }^{+}$and $\mathrm{CD}^{+}{ }^{+} \mathrm{T}$-cells, accelerated Th1 responses, and a broader virus- and epitope-specific repertoire of $\mathrm{CD}^{+}{ }^{+}$T-cells (56). Besides, 1-MT treatment led to improved repair of lung tissue. These results indicate that inhibition of IDO might improve flu vaccine activity, might aid in heterosubtypic immunity and support a faster recovery. This view is also supported by data reporting reduced morbidity rates in IDO KO mice when challenged with RP8 or X31 influenza viruses (54). Especially, IDO deficiency led to enhanced development of memory T-cells, which protected mice from lethal virus infection. Further, it was demonstrated that non-hematopoietic cells from lung-draining lymph nodes were major IDO producing cells in response to X31-induced IFN $\gamma$ secretion. As a feed forward loop, IFN type I and II induced subsequently IDO activity in hematopoietic cells. As a next step, it will be important to translate these findings to human influenza infection and design clinical studies that would allow testing IDO blockade in context of infection and/or vaccination.

\section{ROLE OF IDO IN HBV AND HCV CHRONIC INFECTION}

Indoleamine-2,3-dioxygenase has also been linked to chronic infection with hepatitis B virus (HBV) and hepatitis C virus (HCV) (57). Despite an appropriate $\mathrm{T}$-cell response during the acute phase of HCV infection and subsequent viral clearance, T-cell responses in the chronic phase are weak [summarized by Hiroishi et al. (58)]. A massive amount of $\mathrm{HCV}$-specific CD8 T-cells are recruited to the liver; however, recognition of viral epitopes is barely present. Similarly, in chronic HBV infection, cytotoxic $\mathrm{T}$ lymphocytes (CTLs) show only a weak response against the HBV surface antigen (HBsAg). While the molecular mechanisms of the tolerogenic state in chronic HBV and HCV infection are not completely understood, an increased IDO expression in the liver of patients with chronic HBV or HCV infection has been observed (57). Moreover, high systemic Kyn/Trp ratios in chronically infected patients 
indicate increased IDO activation. In a recent study including 176 patients suffering from chronic HCV infection and 37 healthy controls, it could be shown that Kyn levels correlated with advanced liver inflammation and fibrosis (59). Furthermore, monocytes isolated from PBMCs of $\mathrm{HCV}$ patients differentiated into $\mathrm{IDO}^{+} \mathrm{DC}$ were more potent in inducing Treg cells when activated with LPS or IFN $\gamma$ than those of the control group. Along these lines, in vitro stimulation of the HCV-infected hepatocellular carcinoma cell line Huh7 with IFN $\gamma$ led to an induction of IDO, yet HCV replication was not altered by IDO activity (57).

Yet another mechanism for induction of IDO expression was demonstrated in a murine hepatitis model. Treatment with $\alpha$ galactosylceramide ( $\alpha$-GalCer), a specific agonist for natural killer (NK) cells was able to induce IDO (60). It was speculated that IDO suppresses an overactive immune response triggered by $\mathrm{TNF} \alpha$-producing NK cells and macrophages infiltrating the liver. Following the idea of re-establishing immunocompetent CTLs, wild-type and IDO KO mice were immunized with a combination of $\alpha$-GalCer and HBsAg (61). Upon immunization, expression of the cytokines IL-2 and IL-12b were only increased in IDO KO mice leading to the induction of HBsAg-specific CTLs. Major IDO-expressing cells were $\mathrm{CD}_{11 \mathrm{~b}}{ }^{+} \mathrm{Ly}_{6 \mathrm{G}}{ }^{+}$myeloid-derived suppressor cells (MDSCs) from spleen, which increased in numbers after immunization. They directly inhibited the proliferation of HBsAg-specific CTLs. To assess the role of genes induced by IFN $\alpha$ and/or IFN $\gamma$, Mao et al. co-transfected HepG2 cells with the HBV core promoter and 37 different expression plasmids for IFN $\alpha$ and/or IFN $\gamma$-induced genes (62). Only IDO, APOBEC3G, PKR, and ISG20 reduced HBV DNA levels of more than $60 \%$. IDO was considered as the major mediator of the IFN $\gamma$-induced anti-viral response, since it mediated Trp depletion followed by suppression of HBV replication.

\section{ROLE OF IDO IN OTHER CHRONIC VIRAL INFECTIONS}

Indoleamine-2,3-dioxygenase might also play a role in several other viral infections. While infection with Epstein-Barr virus (EBV) normally causes a self-limited polyclonal lymphoproliferation, it was shown recently that EBV-transformed B-cells express elevated levels of IDO causing Trp degradation to Kyn, which - in turn - suppressed the expression of the activating receptor NK group 2, member D (NKG2D) receptor on the surface of NK cells (63). This might be important since NK cells have been suggested to control the proliferation of EBV-infected B-cells in the acute phase. In the same report, it was shown that IL18 suppressed the effect of Kyn on NKG2D expression. It might be speculated that the suppression of NK cell activation by IDO-expressing EBVinfected B-cells serves as an escape strategy of the virus. Recently, it was shown that in vitro generated macrophages expressed IDO after infection with EBV and displayed T-cell suppressive activities (64). IDO expression induced by TNF $\alpha$ and IL6 signaling was mediated by NFKB and the MAP kinase signaling cascade. Both factors were able to further increase IDO expression, thereby suppressing the proliferative capacity of $\mathrm{CD} 4^{+}$and $\mathrm{CD} 8^{+}$T-cells as well as dampening their cytolytic activity.

Additional evidence for an important role for IDO in viral infection was provided in studies of human papilloma viruses (HPV). Mucosa-tropic HPV are tumorigenic viruses causing genital cancer, e.g., cervical cancer by inducing epithelial hyperplasia (65). Immunotherapy against the tumor is often inefficient because of the existence of a local immunosuppressive tumor milieu with impaired tumor cell antigen presentation and resistance of tumor cells against effector mechanisms of $\mathrm{T}$ cells. The immunosuppressive milieu might be created during the stage of cervical intraepithelial neoplasia (CIN), since numbers of IDO, IFN $\gamma$, IL10, and FoxP3 expressing cells are elevated in CIN compared to normal cervical tissue (66). When HPV16 E7, an envelope- and oncoprotein of HPV was expressed under the keratin-14 promoter (K14E7) in a skin grafting model, graft rejection was prevented suggesting that HPV16E7 induced an immunotolerogenic environment (67). As previously shown, tolerance against E7-expressing skin grafts is based on the induction of IFN $\gamma$ producing natural killer T (NKT)-cells, which not only reduce the capacity of $\mathrm{CD} 11 \mathrm{c}^{+} \mathrm{DC}$ to cross-present antigens to CD8 T-cells (68) but also seem to induce IDO expression. In fact, IDO seems to have a pivotal role in K14E7 graft tolerance, since IDO inhibition by 1-MT leads to rejection of K14E7 skin grafts (67). Furthermore, it was observed that skin grafts recruit higher numbers of DC, which expressed elevated levels of IFN $\gamma$ receptor $(\mathrm{IFN} \gamma \mathrm{R})$. Especially, dermal Langerin ${ }^{+}\left(\mathrm{CD} 207^{+}\right) \mathrm{DC}$ expressed IDO and aided in the recruitment of further DC to the side of transplantation. Clearly, this murine model strongly suggests an important participation of IDO in HPV evasion from host immunity.

Overall, IDO seems to play an important role in chronic viral infections mainly by contributing to the establishment of an immunotolerogenic microenvironment. New strategies to target IDO itself or upstream mechanisms inducing IDO might help in the development of therapeutic drugs for patients with chronic viral infections.

\section{NOVEL ASPECTS OF IDO IN MAJOR BACTERIAL INFECTIONS ROLE OF IDO IN MYCOBACTERIA INFECTIONS}

Tuberculosis ( $\mathrm{Tb})$, caused by mycobacteria, is one of the major human infectious diseases. We and others have linked IDO expression to this disease (69-72). In Tb patients elevated levels of antiinflammatory molecules in the sputum, amongst them IDO have been detected (70). These immune suppressive mediators, also including IL10, TGFßRII, and IL1 receptor antagonist (IL1Rn), have been suggested as biomarkers for $\mathrm{Tb}$. It was assumed that all these inhibitory molecules dampen Th1 responses in the lung thereby contributing to immune-escape of the bacteria. While the direct molecular mechanism of IDO induction in Tb patients is unresolved, it is clear that IFN $\gamma$ and $\mathrm{TNF} \alpha$ play pivotal roles in the containment of Mycobacterium tuberculosis (M. tuberculosis) in humans and in mice (Figure 3). Deficiency of IFN $\gamma$ or TNF $\alpha$ expression, or the lack of the respective receptors cause severe courses of $\mathrm{Tb}$ in mice (73-77). From in vitro studies, there is evidence that $\mathrm{TNF} \alpha$ might play a role during the acute and chronic phase of $\mathrm{Tb}(9,76)$. Moreover, treatment of patients with anti$\mathrm{TNF} \alpha$ antibodies can lead to exacerbation of $\mathrm{Tb}$ and the induction of $\mathrm{Tb}$ sepsis (78). In situ studies clearly demonstrated that granuloma formation after $M$. tuberculosis infection in humans is associated with high expression of IDO in cells of the center and the ring wall structure surrounding the center of the granuloma 


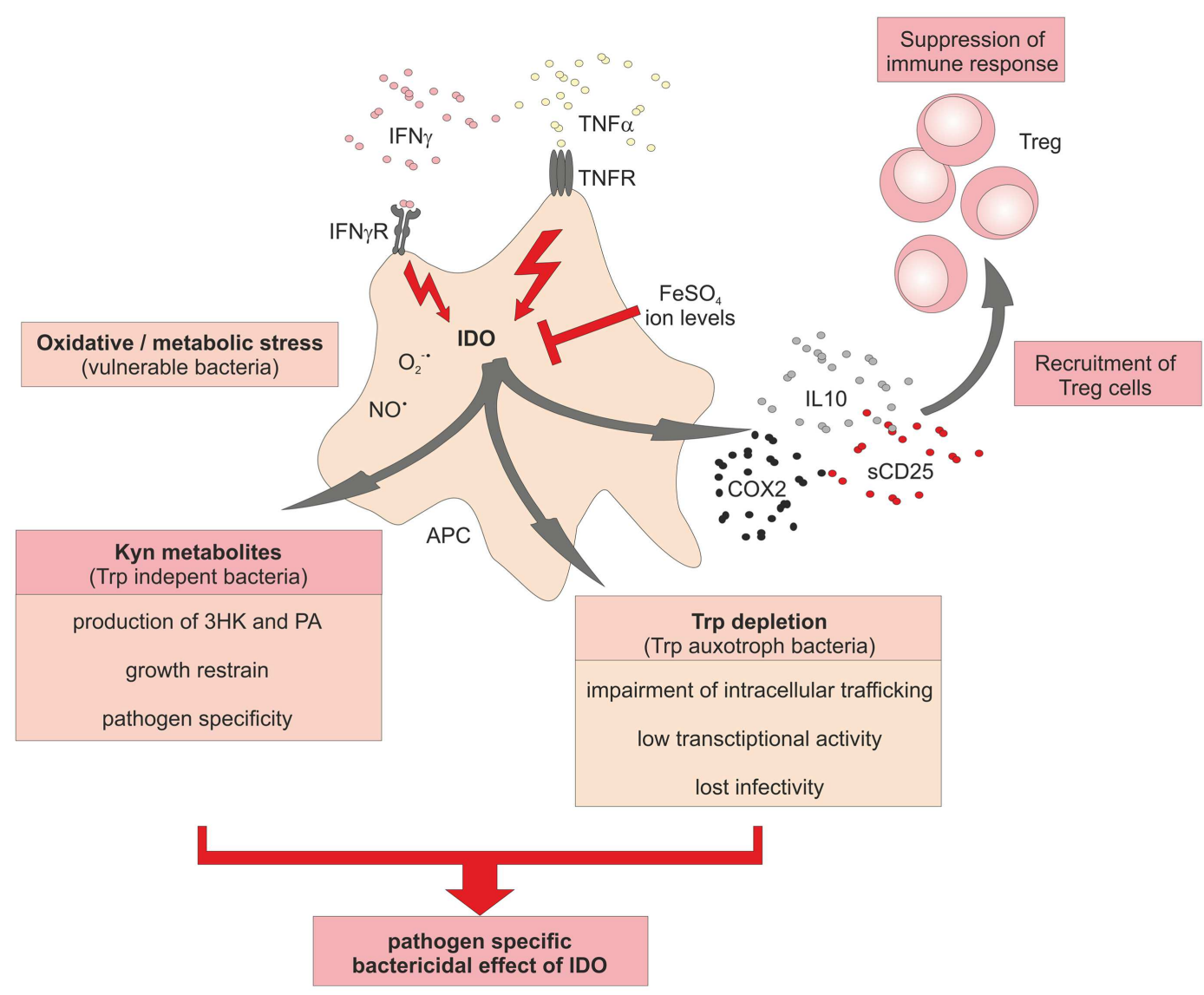

FIGURE 3 | Schematic overview of the central role of IDO in immune responses to bacterial infections. Activation of IDO activity in

bacteria-infected cells induces a potent bactericidal growth restrain to fight against spreading of the infection. Besides the induction of reactive oxygen species (ROS) and nitric oxide radicals, activity of IDO aids in Trp degradation to starve Trp auxotroph bacteria. A further species-specific bactericidal effect of increased IDO activation is the production of toxic Kyn metabolites. Recruitment of Treg cells and increasing levels of free ions might help as negative feedback loop to terminate inflammatory responses.
$(9,71,79)$. Predominant IDO-expressing cells were identified as $\mathrm{CD}^{+} 8^{+}$macrophages and in fewer numbers as CD $11 \mathrm{c}^{+} \mathrm{S} 100^{+} \mathrm{DC}$. Both IDO-expressing myeloid cell populations were surrounded by $\mathrm{CD}^{+}$T-cells. The induction of a tolerogenic milieu including the recruitment of FoxP3 ${ }^{+}$regulatory T-cells by IDO-expressing cells together with depletion of Trp most likely aids in the restriction of bacterial spread. IDO seemed to be absent in biopsies of Mycobacterium leprae (M. leprae) infected skin, suggesting that IDO is not necessarily involved in all granulomatous diseases. However, there is still controversy about this, since a recent report demonstrated expression of IDO in macrophages of leprotic skin lesions (80).

Further controversy about the role of IDO in Tb comes from a recent report demonstrating no essential role for IDO in a murine model of Tb (81). Wild-type as well as IDO KO mice showed comparable bacterial burden, T-cell responses, and survival rates, leading to the conclusion that IDO activity is not required for the control of M. tuberculosis. The authors present no evidence IDO is indeed expressed in the myeloid cell compartment, like in human disease, indicating that this mouse model might not reflect the human situation. In contrast, another report demonstrates a direct connection between IFN $\gamma$ and IDO expression in non-hematopoietic cells, during the chronic phase of murine M. tuberculosis infection (82). In this model, IDO was expressed in endothelial and epithelial cells, and IFN receptor deficiency reduced the levels of expression of IDO in these cells thereby leading to an impaired long-term control of M. tuberculosis (82). However, it was also not shown to which extent IDO activity directly controls $M$. tuberculosis.

There have been numerous studies during the last 20 years demonstrating a correlation between $\mathrm{Tb}$ and depressive disorders in patients (Figure 2) (83-86), but many of the underlying molecular mechanisms remain unclear. To shed some light on the mechanism, O'Connor et al. utilized a BCG vaccination model (87). Mice that showed a depressive-like behavior also represented increased expression of IFN $\gamma, \mathrm{TNF} \alpha$, and IDO. When studying IFN $\gamma$-R deficient mice, many inflammatory mediators were still elevated while the expression of TNF $\alpha$ was attenuated and IFN $\gamma$ and IDO were absent in lung or brain tissue. Furthermore, the lack of IDO activity in IFN $\gamma$-R deficient mice resulted in diminished 
plasma ratios of Kyn/Trp. The authors assumed a synergistic effect of IDO and TNF $\alpha$ on microglia of BCG-treated mice since pretreatment of mice with a TNF $\alpha$ antagonist was able to attenuate $\mathrm{TNF} \alpha$ expression and to abrogate depressive-like behavior. Further studies need to clarify whether TNF $\alpha$ is actually upstream of IDO and blockade of TNF $\alpha$ can reduce IDO expression and function. Downstream of IDO, BCG also increased the expression of 3-hydroxyanthranilic acid oxygenase (3-HAO), which participates in the generation of the neurotoxic Kyn metabolite QA (88). Application of 1-MT also prevented the development of depressive-like behavior after BCG inoculation in mice, suggesting that elevated IDO, like $\mathrm{TNF} \alpha$, contributes to the onset of depressive disorders during chronic inflammation caused by mycobacteria.

\section{ROLE OF IDO IN CHLAMYDIA INFECTIONS}

Indoleamine-2,3-dioxygenase was also shown to be important in the defense against the ubiquitous intracellular bacterium Chlamydia pneumoniae (C. pneumoniae), which causes respiratory tract infections and is associated with chronic diseases like asthma. In general, the life cycle of Chlamydia species can be divided into two phases: (1) a stage of infectious but metabolically inactive form directly after uptake of the bacteria into the host cell, and (2) a stage of differentiation and multiplication enabled by an active metabolism. It can be assumed that immune responses of host cells might differ according to the life cycle of Chlamydia. Njau et al. recently demonstrated that $C$. pneumoniae infection of human moDCinduced IDO expression in a TNF $\alpha$-dependent manner and IDO was sufficient to restrain bacterial growth (89). TNF $\alpha$-dependent bactericidal effects on $C$. pneumoniae were abrogated after supplementation of Trp. Since C. pneumoniae is Trp auxotroph, the authors concluded from these experiments that Trp depletion is detrimental for C. pneumonia growth. In C. pneumoniae-infected THP-1 cells, an induction of IDO, TNF $\alpha$, and neopterin could be demonstrated (90). However, IDO activation in combination with increased Trp degradation as well as IFN $\gamma$ treatment had no effect on numbers or growth of C. pneumoniae in THP-1 cells. This observation was explained by the ability of C. pneumoniae to survive even under conditions of low Trp concentrations, going into a latent state without proliferation and differentiation. An interesting aspect of this study was the comparison of chlamydia infection in THP-1 cells and human endothelial cells. While IDO was already induced in monocytic cells upon infection and was further elevated by IFN $\gamma$, infected and non-infected endothelial cells required IFN $\gamma$ stimulation to induce IDO expression. Only after IFN $\gamma$-treatment, suppression of proliferation of C. pneumoniae in endothelial cells was observed. The authors also argued that the differences between the two cell types might also reflect different stages of the C. pneumoniae infectious cycle. The bacteria might use immune competent monocytes as transportation vessels for systemic dissemination, while endothelial cells might serve as habitats for differentiation and proliferation, especially under iron rich conditions.

An interesting link between IDO and iron metabolism has been suggested by Krausse-Opatz and colleagues (91). In a hepatic cell line infected with Chlamydia trachomatis (C. trachomatis), they could demonstrate that increased intracellular levels of ferrous iron $\mathrm{FeSO}_{4}$ attenuated IFN $\gamma$-induced IDO expression leading to increased infectious yields. Similarly, the human monocytic cell line THP-1 has been shown to be sensitive to low iron concentrations, which showed an inhibitory effect on IFN $\gamma$ signaling resulting in decreased Trp metabolism (92). This observation led to the hypothesis that immune cells retain iron during inflammatory diseases to enable efficient IFN $\gamma$ driven immune responses. On the other hand, reduction of iron levels by deferoxamine did not reconstitute IDO activity, but still suppressed bacterial growth $(90,91)$. Leonhardt et al. addressed whether IDO-mediated Trp depletion is responsible for suppression of bacterial growth of $C$. trachomatis (93). They used HeLa cells, an immortalized cervical carcinoma cell line, as the model for infection. Interestingly, the lack of available Trp in IDO competent HeLa cells led to an impairment of intracellular bacteria trafficking toward the perinuclear microtubule-organizing center after entrance into the host cell. Bacteria displayed low transcriptional activity, lost their infectivity, and remained scattered in the periphery of the HeLa cells. Since most of the recent work concerning the influence of iron ions has been performed in cell line models, it remains an unanswered question, whether these observations will hold true, once primary human cells are used for analysis.

\section{ROLE OF IDO IN COMMUNITY-ACOUIRED PNEUMONIA AND SEPSIS}

Another area of great interest during the last years has been the function of IDO during community-acquired pneumonia (CAP) and sepsis. Already in 2005, increased Kyn levels in trauma patients with bacteremic sepsis, respiratory distress syndrome, or multi organ dysfunction/failure pointed toward a role for IDO in sepsis (94). In a larger cohort-study, Suzuki and colleagues investigated 129 patients and 64 healthy controls and revealed increased Kyn/Trp ratios as prognostic marker for severity and morbidity of CAP caused by multiple pathogens (95). Along these lines, several independent studies reported increased IDO activity as predictor of severity and mortality of sepsis (96-98). Elevated Kyn/Trp ratios as indicator of IDO activity in plasma of sepsis patients also correlated with elevated levels of IFN $\gamma$ and IL10, which were also shown to further trigger IDO activity (96). Furthermore, these patients show reduced $\mathrm{CD}^{+}$and $\mathrm{CD} 8^{+}$T-cell counts similarly pointing to an overall impairment of immune functions during sepsis. There was also an inverse correlation between elevated $\mathrm{Kyn} / \mathrm{Trp}$ ratios and NO-dependent microvascular reactivity as a surrogate marker for endothelial cell function, as mean arterial or diastolic blood pressure were reduced. Direct measurement of IDO activity in patients with sepsis or septic shock showed a gradual increase of IDO activity with severity of sepsis, which was directly associated with mortality (97). The major sources of IDO were circulating $\mathrm{CD} 14^{+}$monocytes, which were increased both absolutely and relatively compared to other white blood cells during sepsis. Interestingly, ex vivo stimulation of monocytes from septic patients with IFN $\gamma$ led to the induction of functional IDO and was found to be independent of NFKB signaling while other TLR agonists like LPS-induced IDO expression in an NFKB dependent fashion (97).

Along these lines, hints for a novel IDO-inducing mechanism were found in a murine mouse model in which the induction of IDO in context of sepsis was investigated. Mice which are deficient in serine/threonine kinase, general control non-derepressible 2 (GCN2) gene were protected from endotoxic shock (99). This 
was associated with a rapid induction of IDO in spleen and an increased Kyn/Trp ratio in serum suggesting that elevated IDO levels in sepsis might actually be beneficial. However, this does not seem to be necessarily the case since IDO deficient mice also are resistant against LPS-induced septic shock (100). Similarly, inhibition of IDO activity by 1-MT during endotoxin shock in vivo was associated with increased survival (100). Whether these results can be translated to humans has to be proven. In this context, it is interesting to mention that application of GMCSF in sepsis patients was associated with suppression of IDO activity and reduction of free Kyn metabolites (101). Experimental proof for concomitant improvement of antibacterial defense has to be further investigated.

Overall, IDO also seems to play a role during clinically relevant infections such as CAP and sepsis. Whether IDO might become a therapeutic target in these patients is still to be investigated.

\section{ROLE OF IDO IN LISTERIA INFECTIONS}

During the last years, we have defined the role of IDO in human listeriosis $(8,9,23,69,79,93,102)$. Listeriosis is a foodborne disease caused by oral infection with Listeria monocytogenes (L. monocytogenes). Newborn infants are prone to infections due to incompletely developed cell-mediated immunity. Early on, we could demonstrate that induction of IDO in myeloid cells after L. monocytogenes infection is TNF $\alpha$ dependent (9). Chronic listeriosis is characterized by the development of granulomatous structures encapsulating bacteria-infected cells to restrain bacterial spreading. IDO-expressing $\mathrm{CD}^{+} 8^{+}$macrophages and $\mathrm{S} 100^{+} \mathrm{CD} 11 \mathrm{c}^{+}$ DC, but not T- or B-cells, are part of the ring wall structure in these granuloma. When analyzing the effect of L. monocytogenes infection on DC function, we observed an inhibitory effect of these DC on T-cell proliferation and cytokine expression. Furthermore, we demonstrated that the inhibitory effect is mediated by IDO and the TNF $\alpha$-dependent production of suppressive molecules like IL10, COX2, and soluble CD25 (69). Initial experiments addressing the IDO-mediated inhibitory effects on T-cells suggested that IDO-mediated Trp depletion and also the production of toxic metabolites were responsible for the observed loss of T-cell proliferation and cytokine production $(69,102)$. More recently, we were interested to understand whether bactericidal effects exerted by IDO-expressing human myeloid cells is mainly due to Trp depletion or toxic metabolites (23). Earlier work in mice and in human cells, as well as in other bacterial infections showed conflicting results concerning the role of these two bactericidal mechanisms. Using primary human macrophages and DCs, we could show unequivocally that it is not Trp depletion but rather Kyn metabolites that exert the bactericidal effect against $L$. monocytogenes. Especially, 3-hydroxy-kynurenine (3HK) was the most potent Kyn metabolite. Moreover, this bactericidal effect was also seen for other Listeria strains including Listeria innocua. It is important to note that these findings only reflect IDO biology in humans, since we could also clearly show that IDO is not induced in murine DC and macrophages after infection with L. monocytogenes. In contrast, murine L. monocytogenes infected myeloid cells produced iNOS instead of IDO. One explanation of the observed species-specific differences might be a differential expression of the iNOS cofactor tetrahydrobiopterin, which is expressed by murine primary macrophages as well as murine macrophage cell lines after activation with IFN $\gamma$ and LPS $(103,104)$. In fact, murine IFN $\gamma$ stimulated macrophages showed a strong correlation between tetrahydrobiopterin and NO levels (104). In contrast, tetrahydrobiopterin was shown to be expressed only at very low levels in human monocytes and macrophages (104, 105). A further explanation for this divergent usage of IDO and NO between mice and men came from a study, which revealed an inhibitory effect of NO on IDO in primary IFN $\gamma$-activated human peripheral mononuclear cells and macrophages (106). An interaction of NO with the heme iron at the active site of IDO preventing the conversion of ferric iron, necessary for IDO activity, has been proposed to be responsible for the inhibitory effect of NO on IDO (107). IDO inhibition might also rely on rapid removal of oxygen radicals by NO, which are required for IDO activity $(108,109)$. Such a clear-cut species-specific difference in usage of effector molecules as well as diverging susceptibilities against pathogens between mice and men are not too surprising since both species have evolved in different habitats, being exposed to completely different sets of pathogens. These observations further support the notion that one needs to be very careful when studying murine IDO in infection models and translating gained knowledge back to human diseases such as listeriosis or $\mathrm{Tb}$.

\section{SUMMARY/CONCLUDING REMARKS}

Recent findings have clearly revealed that elevated IDO expression is a hallmark of major human viral infections including $\mathrm{HIV}, \mathrm{HBV}, \mathrm{HCV}$, or influenza, and also major bacterial infections such as Tb, CAP, listeriosis, or sepsis. Besides Trp depletion, production of ROS or the modulation of Trp metabolism by iron ions via IFN $\gamma$ have to be considered as part of a complex network participating in the fight against pathogens. An elevated $\mathrm{Kyn} / \mathrm{Trp}$ ratio as a surrogate for IDO activity seems to be a hallmark for these infectious diseases and as demonstrated for sepsis patients seem to correlate with the severity of disease. So far, the major role of elevated IDO activity has not been definitely established. Both anti-pathogen and immunosuppressive mechanisms have been suggested. In this scenario, IDO activity might be a dual sword, fighting the pathogen directly by a metabolic mechanism, while keeping an overwhelming immune response in check. Whether this delicate balance between pathogen defense and host protection from lateral damage induced by IDO could be utilized therapeutically to further optimize the host response during infection remains to be seen. So far, it is not clear whether a further increase of IDO activity would indeed be beneficial. It might enhance the anti-pathogenic effect, but further elevating immunosuppression might actually be detrimental to the host during infection.

In fact, data from septic patients as well as studies from murine sepsis models utilizing LPS to induce septic shock would actually speak against enhancing IDO activity. On the contrary, in these models, depletion of IDO function is actually beneficial to the host. As exemplified above, interpreting the role of IDO for human $\mathrm{Tb}$ might be very misleading when based on murine models that do not reflect human disease properly. Moreover, we have clearly established that IDO is differentially regulated in murine and human myeloid cells in response to infection 
with L. monocytogenes and probably also other viral and bacterial infections. Particularly when studying the myeloid compartment, we strongly recommend to study regulation and function of IDO first in humans. If IDO is involved, the findings should be translated into the murine model. However, if there is no evidence for IDO regulation in the same cellular compartment in the murine infection model, then it will be necessary to either use other more informative animal models or to apply other approaches in the human setting. For future research, it will be extremely important to develop structured datasets that can be quickly interrogated to understand whether gene function observed in human disease is also apparent in major animal models, particularly the murine system. So far, such data are missing.

\section{ACKNOWLEDGMENTS}

We thank Heike Weigardt for carefully reading the manuscript. This work was supported by grants of the DFG to Joachim L. Schultze (Sonderforschungsbereich 645, SFB 704, SFB 832, INST 217/575-1, INST 217/576-1, and INST 217/577-1). Joachim L. Schultze is member of the Excellence Cluster ImmunoSensation, and receives funding from the People Programme (Marie Curie Actions) of the European Union's Seventh Framework Programme FP7/2077-2013 under REA grant agreement no. 317445.

\section{REFERENCES}

1. Pfefferkorn ER. Interferon gamma blocks the growth of Toxoplasma gondii in human fibroblasts by inducing the host cells to degrade tryptophan. Proc Natl Acad Sci U S A (1984) 81:908-12. doi:10.1073/pnas.81.3.908

2. Taylor MW, Feng GS. Relationship between interferon-gamma, indoleamine 2,3-dioxygenase, and tryptophan catabolism. FASEB $J$ (1991) 5: 2516-22.

3. Werner ER, Bitterlich G, Fuchs D, Hausen A, Reibnegger G, Szabo G, et al. Human macrophages degrade tryptophan upon induction by interferongamma. Life Sci (1987) 41:273-80. doi:10.1016/0024-3205(87)90149-4

4. Carlin JM, Borden EC, Sondel PM, Byrne GI. Interferon-induced indoleamine 2,3-dioxygenase activity in human mononuclear phagocytes. J Leukoc Biol (1989) 45:29-34.

5. Munn DH, Mellor AL. Indoleamine 2,3 dioxygenase and metabolic control of immune responses. Trends Immunol (2013) 34:137-43. doi:10.1016/j.it.2012. 10.001

6. Curti A, Trabanelli S, Salvestrini V, Baccarani M, Lemoli RM. The role of indoleamine 2,3-dioxygenase in the induction of immune tolerance: focus on hematology. Blood (2009) 113:2394-401. doi:10.1182/blood-2008-07-144485

7. Popov A, Schultze JL. IDO-expressing regulatory dendritic cells in cancer and chronic infection. J Mol Med (Berl) (2008) 86:145-60. doi:10.1007/s00109007-0262-6

8. von Bergwelt-Baildon MS, Popov A, Saric T, Chemnitz J, Classen S, Stoffel MS, et al. CD25 and indoleamine 2,3-dioxygenase are up-regulated by prostaglandin E2 and expressed by tumor-associated dendritic cells in vivo: additional mechanisms of T-cell inhibition. Blood (2006) 108:228-37. doi:10. 1182/blood-2005-08-3507

9. Popov A, Abdullah Z, Wickenhauser C, Saric T, Driesen J, Hanisch FG, et al. Indoleamine 2,3-dioxygenase-expressing dendritic cells form suppurative granulomas following Listeria monocytogenes infection. JClin Invest (2006) 116:3160-70. doi:10.1172/JCI28996

10. Aune TM, Pogue SL. Inhibition of tumor cell growth by interferon-gamma is mediated by two distinct mechanisms dependent upon oxygen tension: induction of tryptophan degradation and depletion of intracellular nicotinamide adenine dinucleotide. J Clin Invest (1989) 84:863-75. doi:10.1172/JCI114247

11. Munn DH, Zhou M, Attwood JT, Bondarev I, Conway SJ, Marshall B, et al. Prevention of allogeneic fetal rejection by tryptophan catabolism. Science (1998) 281:1191-3. doi:10.1126/science.281.5380.1191
12. Puccetti P, Grohmann U. IDO and regulatory T cells: a role for reverse signalling and non-canonical NF-kappaB activation. Nat Rev Immunol (2007) 7:817-23. doi:10.1038/nri2163

13. Mellor AL, Munn DH. IDO expression by dendritic cells: tolerance and tryptophan catabolism. Nat Rev Immunol (2004) 4:762-74. doi:10.1038/ nri1457

14. Carlin JM, Borden EC, Byrne GI. Interferon-induced indoleamine 2,3dioxygenase activity inhibits Chlamydia psittaci replication in human macrophages. J Interferon Res (1989) 9:329-37. doi:10.1089/jir.1989.9.329

15. Murray HW, Szuro-Sudol A, Wellner D, Oca MJ, Granger AM, Libby DM, et al. Role of tryptophan degradation in respiratory burst-independent antimicrobial activity of gamma interferon-stimulated human macrophages. Infect Immun (1989) 57:845-9.

16. Schmitz JL, Carlin JM, Borden EC, Byrne GI. Beta interferon inhibits Toxoplasma gondii growth in human monocyte-derived macrophages. Infect Immun (1989) 57:3254-6.

17. Adams O, Besken K, Oberdörfer C, MacKenzie CR, Rüssing D, Däubener W. Inhibition of human herpes simplex virus type 2 by interferon gamma and tumor necrosis factor alpha is mediated by indoleamine 2,3-dioxygenase. Microbes Infect (2004) 6:806-12. doi:10.1016/j.micinf.2004.04.007

18. Bodaghi B, Goureau O, Zipeto D, Laurent L, Virelizier JL, Michelson S. Role of IFN-gamma-induced indoleamine 2,3 dioxygenase and inducible nitric oxide synthase in the replication of human cytomegalovirus in retinal pigment epithelial cells. J Immunol (1999) 162:957-64.

19. Obojes K, Andres O, Kim KS, Daubener W, Schneider-Schaulies J. Indoleamine 2,3-dioxygenase mediates cell type-specific anti-measles virus activity of gamma interferon. J Virol (2005) 79:7768-76. doi:10.1128/JVI.79.12.77687776.2005

20. Terajima M, Leporati AM. Role of indoleamine 2,3-dioxygenase in antiviral activity of interferon-gamma against vaccinia virus. Viral Immunol (2005) 18:722-9. doi:10.1089/vim.2005.18.722

21. Loughman JA, Hunstad DA. Induction of indoleamine 2,3-dioxygenase by uropathogenic bacteria attenuates innate responses to epithelial infection. J Infect Dis (2012) 205:1830-9. doi:10.1093/infdis/jis280

22. Zelante T, Fallarino F, Bistoni F, Puccetti P, Romani L. Indoleamine 2,3dioxygenase in infection: the paradox of an evasive strategy that benefits the host. Microbes Infect (2009) 11:133-41. doi:10.1016/j.micinf.2008.10.007

23. Niño-Castro A, Abdullah Z, Popov A, Thabet Y, Beyer M, Knolle P, et al. The IDO1-induced kynurenines play a major role in the antimicrobial effect of human myeloid cells against Listeria monocytogenes. Innate Immun (2014) 20:401-11. doi:10.1177/1753425913496442

24. Akaike T, Maeda H. Nitric oxide and virus infection. Immunology (2000) 101:300-8. doi:10.1046/j.1365-2567.2000.00142.x

25. Boasso A, Shearer GM. How does indoleamine 2,3-dioxygenase contribute to HIV-mediated immune dysregulation. Curr Drug Metab (2007) 8:217-23. doi: $10.2174 / 138920007780362527$

26. Larsson M, Shankar EM, Che KF, Saeidi A, Ellegård R, Barathan M, et al. Molecular signatures of T-cell inhibition in HIV-1 infection. Retrovirology (2013) 10:31. doi:10.1186/1742-4690-10-31

27. Watanabe D, Uehira T, Yonemoto H, Bando H, Ogawa Y, Yajima K, et al. Sustained high levels of serum interferon-gamma during HIV-1 infection: a specific trend different from other cytokines. Viral Immunol (2010) 23:619-25. doi:10.1089/vim.2010.0065

28. Schroecksnadel K, Zangerle R, Bellmann-Weiler R, Garimorth K, Weiss G, Fuchs D. Indoleamine-2, 3-dioxygenase and other interferon-gammamediated pathways in patients with human immunodeficiency virus infection. Curr Drug Metab (2007) 8:225-36. doi:10.2174/138920007780362608

29. Werner ER, Fuchs D, Hausen A, Jaeger H, Reibnegger G, Werner-Felmayer G, et al. Tryptophan degradation in patients infected by human immunodeficiency virus. Biol Chem Hoppe Seyler (1988) 369:337-40. doi:10.1515/bchm3. 1988.369.1.337

30. Boasso A, Herbeuval JP, Hardy AW, Anderson SA, Dolan MJ, Fuchs D, et al. HIV inhibits CD4+ T-cell proliferation by inducing indoleamine 2,3-dioxygenase in plasmacytoid dendritic cells. Blood (2007) 109:3351-9. doi:10.1182/blood2006-07-034785

31. Boasso A, Hardy AW, Anderson SA, Dolan MJ, Shearer GM. HIV-induced type I interferon and tryptophan catabolism drive $\mathrm{T}$ cell dysfunction despite phenotypic activation. PLoS One (2008) 3:e2961. doi:10.1371/journal.pone. 0002961 
32. Beyer M, Karbach J, Mallmann MR, Zander T, Eggle D, Classen S, et al. Cancer vaccine enhanced, non-tumor-reactive CD8(+) T cells exhibit a distinct molecular program associated with "division arrest anergy". Cancer Res (2009) 69:4346-54. doi:10.1158/0008-5472.CAN-08-3796

33. Planes R, Bahraoui E. HIV-1 Tat protein induces the production of IDO in human monocyte derived-dendritic cells through a direct mechanism: effect on T cells proliferation. PLoS One (2013) 8:e74551. doi:10.1371/journal.pone. 0074551

34. Boasso A, Vaccari M, Fuchs D, Hardy AW, Tsai WP, Tryniszewska E, et al. Combined effect of antiretroviral therapy and blockade of IDO in SIV-infected rhesus macaques. J Immunol (2009) 182:4313-20. doi:10.4049/ jimmunol.0803314

35. Soumelis V, Scott I, Gheyas F, Bouhour D, Cozon G, Cotte L, et al. Depletion of circulating natural type 1 interferon-producing cells in HIV-infected AIDS patients. Blood (2001) 98:906-12. doi:10.1182/blood.V98.4.906

36. Malleret B, Manéglier B, Karlsson I, Lebon P, Nascimbeni M, Perié L, et al. Primary infection with simian immunodeficiency virus: plasmacytoid dendritic cell homing to lymph nodes, type I interferon, and immune suppression. Blood (2008) 112:4598-608. doi:10.1182/blood-2008-06-162651

37. Pacanowski J, Kahi S, Baillet M, Lebon P, Deveau C, Goujard C, et al. Reduced blood CD123+ (lymphoid) and CD11c+ (myeloid) dendritic cell numbers in primary HIV-1 infection. Blood (2001) 98:3016-21. doi:10.1182/blood.V98. 10.3016

38. Tan PH, Beutelspacher SC, Xue SA, Wang YH, Mitchell P, McAlister JC, et al. Modulation of human dendritic-cell function following transduction with viral vectors: implications for gene therapy. Blood (2005) 105:3824-32. doi:10.1182/blood-2004-10-3880

39. Fallarino F, Grohmann U, Hwang KW, Orabona C, Vacca C, Bianchi R, et al. Modulation of tryptophan catabolism by regulatory $\mathrm{T}$ cells. Nat Immunol (2003) 4:1206-12. doi:10.1038/ni1003

40. Munn DH, Sharma MD, Mellor AL. Ligation of B7-1/B7-2 by human CD4+ T cells triggers indoleamine 2,3-dioxygenase activity in dendritic cells. J Immunol (2004) 172:4100-10. doi:10.4049/jimmunol.172.7.4100

41. Favre D, Mold J, Hunt PW, Kanwar B, Loke P, Seu L, et al. Tryptophan catabolism by indoleamine 2,3-dioxygenase 1 alters the balance of TH17 to regulatory T cells in HIV disease. Sci Transl Med (2010) 2:32ra36. doi:10.1126/ scitranslmed.3000632

42. Aandahl EM, Michaelsson J, Moretto WJ, Hecht FM, Nixon DF. Human CD4+ CD25+ regulatory T cells control T-cell responses to human immunodeficiency virus and cytomegalovirus antigens. J Virol (2004) 78:2454-9. doi:10.1128/JVI.78.5.2454-2459.2004

43. Boasso A, Vaccari M, Hryniewicz A, Fuchs D, Nacsa J, Cecchinato V, et al. Regulatory T-cell markers, indoleamine 2,3-dioxygenase, and virus levels in spleen and gut during progressive simian immunodeficiency virus infection. J Virol (2007) 81:11593-603. doi:10.1128/JVI.00760-07

44. Cecchinato V, Tryniszewska E, Ma ZM, Vaccari M, Boasso A, Tsai WP, et al. Immune activation driven by CTLA- 4 blockade augments viral replication at mucosal sites in simian immunodeficiency virus infection. J Immunol (2008) 180:5439-47. doi:10.4049/jimmunol.180.8.5439

45. Vaccari M, Boasso A, Fenizia C, Fuchs D, Hryniewicz A, Morgan T, et al. Fatal pancreatitis in simian immunodeficiency virus SIV(mac251)-infected macaques treated with $2^{\prime}, 3^{\prime}$-dideoxyinosine and stavudine following cytotoxicT-lymphocyte-associated antigen 4 and indoleamine 2,3-dioxygenase blockade. J Virol (2012) 86:108-13. doi:10.1128/JVI.05609-11

46. Hoshi M, Saito K, Hara A, Taguchi A, Ohtaki H, Tanaka R, et al. The absence of IDO upregulates type I IFN production, resulting in suppression of viral replication in the retrovirus-infected mouse. J Immunol (2010) 185:3305-12. doi:10.4049/jimmunol.0901150

47. O'Connor MA, Green WR. The role of indoleamine 2,3-dioxygenase in LPBPM5 murine retroviral disease progression. Virol J (2013) 10:154. doi:10. 1186/1743-422X-10-154

48. Widner B, Ledochowski M, Fuchs D. Interferon-gamma-induced tryptophan degradation: neuropsychiatric and immunological consequences. Curr Drug Metab (2000) 1:193-204. doi:10.2174/1389200003339063

49. Widner B, Laich A, Sperner-Unterweger B, Ledochowski M, Fuchs D. Neopterin production, tryptophan degradation, and mental depression - what is the link? Brain Behav Immun (2002) 16:590-5. doi:10.1016/S0889-1591(02)00006-5
50. Samikkannu T, Rao KV, Gandhi N, Saxena SK, Nair MP. Human immunodeficiency virus type 1 clade $\mathrm{B}$ and $\mathrm{C}$ Tat differentially induce indoleamine 2,3dioxygenase and serotonin in immature dendritic cells: implications for neuroAIDS. J Neurovirol (2010) 16:255-63. doi:10.3109/13550284.2010.497809

51. Samikkannu T, Saiyed ZM, Rao KV, Babu DK, Rodriguez JW, Papuashvili MN, et al. Differential regulation of indoleamine-2,3-dioxygenase (IDO) by HIV type 1 clade B and C Tat protein. AIDS Res Hum Retroviruses (2009) 25:329-35. doi:10.1089/aid.2008.0225

52. Lawson MA, Kelley KW, Dantzer R. Intracerebroventricular administration of HIV-1 Tat induces brain cytokine and indoleamine 2,3-dioxygenase expression: a possible mechanism for AIDS comorbid depression. Brain Behav Immun (2011) 25:1569-75. doi:10.1016/j.bbi.2011.05.006

53. Yoshida R, Urade Y, Tokuda M, Hayaishi O. Induction of indoleamine 2,3dioxygenase in mouse lung during virus infection. Proc Natl Acad Sci U S A (1979) 76:4084-6. doi:10.1073/pnas.76.8.4084

54. Huang L, Li L, Klonowski KD, Tompkins SM, Tripp RA, Mellor AL. Induction and role of indoleamine 2,3 dioxygenase in mouse models of influenza a virus infection. PLoS One (2013) 8:e66546. doi:10.1371/journal.pone.0066546

55. Fox JM, Sage LK, Huang L, Barber J, Klonowski KD, Mellor AL, et al. Inhibition of indoleamine 2,3-dioxygenase enhances the T-cell response to influenza virus infection. J Gen Virol (2013) 94:1451-61. doi:10.1099/vir.0.053124-0

56. Sage LK, Fox JM, Mellor AL, Tompkins SM, Tripp RA. Indoleamine 2,3dioxygenase (IDO) activity during the primary immune response to influenza infection modifies the memory $\mathrm{T}$ cell response to influenza challenge. Viral Immunol (2014) 27:112-23. doi:10.1089/vim.2013.0105

57. Larrea E, Riezu-Boj JI, Gil-Guerrero L, Casares N, Aldabe R, Sarobe P, et al. Upregulation of indoleamine 2,3-dioxygenase in hepatitis $\mathrm{C}$ virus infection. J Virol (2007) 81:3662-6. doi:10.1128/JVI.02248-06

58. Hiroishi K, Ito T, Imawari M. Immune responses in hepatitis $\mathrm{C}$ virus infection and mechanisms of hepatitis $\mathrm{C}$ virus persistence. J Gastroenterol Hepatol (2008) 23:1473-82. doi:10.1111/j.1440-1746.2008.05475.x

59. Higashitani K, Kanto T, Kuroda S, Yoshio S, Matsubara T, Kakita N, et al. Association of enhanced activity of indoleamine 2,3-dioxygenase in dendritic cells with the induction of regulatory T cells in chronic hepatitis C infection. J Gastroenterol (2013) 48:660-70. doi:10.1007/s00535-012-0667-z

60. Ito H, Hoshi M, Ohtaki H, Taguchi A, Ando K, Ishikawa T, et al. Ability of IDO to attenuate liver injury in alpha-galactosylceramide-induced hepatitis model. J Immunol (2010) 185:4554-60. doi:10.4049/jimmunol.0904173

61. Ito H, Ando T, Ando K, Ishikawa $\mathrm{T}$, Saito K, Moriwaki H, et al. Induction of HBsAg-specific cytotoxic $\mathrm{T}$ lymphocytes can be up-regulated by the inhibition of indoleamine 2, 3-dioxygenase activity. Immunology (2014) 142:614-23. doi:10.1111/imm.12274

62. Mao R, Zhang J, Jiang D, Cai D, Levy JM, Cuconati A, et al. Indoleamine 2,3dioxygenase mediates the antiviral effect of gamma interferon against hepatitis B virus in human hepatocyte-derived cells. J Virol (2011) 85:1048-57. doi:10.1128/JVI.01998-10

63. Song H, Park H, Kim J, Park G, Kim YS, Kim SM, et al. IDO metabolite produced by EBV-transformed B cells inhibits surface expression of NKG2D in NK cells via the c-Jun N-terminal kinase (JNK) pathway. Immunol Lett (2011) 136:187-93. doi:10.1016/j.imlet.2011.01.009

64. Liu WL, Lin YH, Xiao H, Xing S, Chen H, Chi PD, et al. Epstein-Barr Virus infection induces indoleamine 2,3-dioxygenase expression in human monocytederived macrophages through p38/MAPK and NF-kappaB pathways: impairment in T cell functions. J Virol (2014) 88:6660-71. doi:10.1128/JVI.03678-13

65. zur Hausen H, de Villiers EM, Gissmann L. Papillomavirus infections and human genital cancer. Gynecol Oncol (1981) 12:S124-8. doi:10.1016/00908258(81)90067-6

66. Kobayashi A, Weinberg V, Darragh T, Smith-McCune K. Evolving immunosuppressive microenvironment during human cervical carcinogenesis. Mucosal Immunol (2008) 1:412-20. doi:10.1038/mi.2008.33

67. Mittal D, Kassianos AJ, Tran LS, Bergot AS, Gosmann C, Hofmann J, et al. Indoleamine 2,3-dioxygenase activity contributes to local immune suppression in the skin expressing human papillomavirus oncoprotein e7. J Invest Dermatol (2013) 133:2686-94. doi:10.1038/jid.2013.222

68. Mattarollo SR, Yong M, Gosmann C, Choyce A, Chan D, Leggatt GR, et al. NKT cells inhibit antigen-specific effector CD8 T cell induction to skin viral proteins. J Immunol (2011) 187:1601-8. doi:10.4049/jimmunol.1100756 
69. Popov A, Driesen J, Abdullah Z, Wickenhauser C, Beyer M, Debey-Pascher S, et al. Infection of myeloid dendritic cells with Listeria monocytogenes leads to the suppression of $\mathrm{T}$ cell function by multiple inhibitory mechanisms. J Immunol (2008) 181:4976-88. doi:10.4049/jimmunol.181.7.4976

70. Almeida AS, Lago PM, Boechat N, Huard RC, Lazzarini LC, Santos AR, et al. Tuberculosis is associated with a down-modulatory lung immune response that impairs Th1-type immunity. J Immunol (2009) 183:718-31. doi:10.4049/ jimmunol.0801212

71. Li Q, Li L, Liu Y, Fu X, Qiao D, Wang H, et al. Pleural fluid from tuberculous pleurisy inhibits the functions of $\mathrm{T}$ cells and the differentiation of Th1 cells via immunosuppressive factors. Cell Mol Immunol (2011) 8:172-80. doi: $10.1038 / \mathrm{cmi} .2010 .80$

72. Suzuki Y, Suda T, Asada K, Miwa S, Suzuki M, Fujie M, et al. Serum indoleamine 2,3-dioxygenase activity predicts prognosis of pulmonary tuberculosis. Clin Vaccine Immunol (2012) 19:436-42. doi:10.1128/CVI.05402-11

73. Jouanguy E, Lamhamedi-Cherradi S, Altare F, Fondanèche MC, Tuerlinckx D, Blanche S, et al. Partial interferon-gamma receptor 1 deficiency in a child with tuberculoid bacillus Calmette-Guerin infection and a sibling with clinical tuberculosis. J Clin Invest (1997) 100:2658-64. doi:10.1172/JCI119810

74. Cooper AM, Dalton DK, Stewart TA, Griffin JP, Russell DG, Orme IM. Disseminated tuberculosis in interferon gamma gene-disrupted mice. J Exp Med (1993) 178:2243-7. doi:10.1084/jem.178.6.2243

75. Flynn JL, Chan J, Triebold KJ, Dalton DK, Stewart TA, Bloom BR. An essential role for interferon gamma in resistance to Mycobacterium tuberculosis infection. J Exp Med (1993) 178:2249-54. doi:10.1084/jem.178.6.2249

76. Bekker LG, Moreira AL, Bergtold A, Freeman S, Ryffel B, Kaplan G. Immunopathologic effects of tumor necrosis factor alpha in murine mycobacterial infection are dose dependent. Infect Immun (2000) 68:6954-61. doi:10. 1128/IAI.68.12.6954-6961.2000

77. Botha T, Ryffel B. Reactivation of latent tuberculosis infection in TNF-deficient mice. J Immunol (2003) 171:3110-8. doi:10.4049/jimmunol.171.6.3110

78. Keane J, Gershon S, Wise RP, Mirabile-Levens E, Kasznica J, Schwieterman WD, et al. Tuberculosis associated with infliximab, a tumor necrosis factor alpha-neutralizing agent. N Engl J Med (2001) 345:1098-104. doi:10.1056/ NEJMoa011110

79. von Bubnoff D, Scheler M, Wilms H, Wenzel J, von Bubnoff N, Häcker $\mathrm{G}$, et al. Indoleamine 2,3-dioxygenase-expressing myeloid dendritic cells and macrophages in infectious and noninfectious cutaneous granulomas. J Am Acad Dermatol (2011) 65:819-32. doi:10.1016/j.jaad.2010.07.050

80. de SouzaSales J, Lara FA, Amadeu TP, de OliveiraFulco T, da CostaNery JA, Sampaio EP, et al. The role of indoleamine 2, 3-dioxygenase in lepromatous leprosy immunosuppression. Clin Exp Immunol (2011) 165:251-63. doi:10.1111/j.1365-2249.2011.04412.x

81. Blumenthal A, Nagalingam G, Huch JH, Walker L, Guillemin GJ, Smythe GA, et al. M. tuberculosis induces potent activation of IDO-1, but this is not essential for the immunological control of infection. PLoS One (2012) 7:e37314. doi:10.1371/journal.pone.0037314

82. Desvignes L, Ernst JD. Interferon-gamma-responsive nonhematopoietic cells regulate the immune response to Mycobacterium tuberculosis. Immunity (2009) 31:974-85. doi:10.1016/j.immuni.2009.10.007

83. Westaway MS, Wolmarans L. Depression and self-esteem: rapid screening for depression in black, low literacy, hospitalized tuberculosis patients. Soc Sci Med (1992) 35:1311-5. doi:10.1016/0277-9536(92)90184-R

84. Trenton AJ, Currier GW. Treatment of comorbid tuberculosis and depression. Prim Care Companion J Clin Psychiatry (2001) 3:236-43. doi:10.4088/PCC. v03n0610

85. Husain MO, Dearman SP, Chaudhry IB, Rizvi N, Waheed W. The relationship between anxiety, depression and illness perception in tberculosis patients in Pakistan. Clin Pract Epidemiol Ment Health (2008) 4:4. doi:10.1186/17450179-4-4

86. Issa BA, Yussuf AD, Kuranga SI. Depression comorbidity among patients with tuberculosis in a university teaching hospital outpatient clinic in Nigeria. Ment Health Fam Med (2009) 6:133-8.

87. O'Connor JC, André C, Wang Y, Lawson MA, Szegedi SS, Lestage J, et al. Interferon-gamma and tumor necrosis factor-alpha mediate the upregulation of indoleamine 2,3-dioxygenase and the induction of depressive-like behavior in mice in response to bacillus Calmette-Guerin. J Neurosci (2009) 29: 4200-9. doi:10.1523/JNEUROSCI.5032-08.2009

88. O'Connor JC, Lawson MA, André C, Briley EM, Szegedi SS, Lestage J, et al. Induction of IDO by bacille Calmette-Guerin is responsible for development of murine depressive-like behavior. J Immunol (2009) 182:3202-12. doi:10.4049/jimmunol.0802722

89. Njau F, Geffers R, Thalmann J, Haller H, Wagner AD. Restriction of Chlamydia pneumoniae replication in human dendritic cell by activation of indoleamine 2,3-dioxygenase. Microbes Infect (2009) 11:1002-10. doi:10.1016/j.micinf. 2009.07.006

90. Bellmann-Weiler R, Martinz V, Kurz K, Engl S, Feistritzer C, Fuchs D, et al. Divergent modulation of Chlamydia pneumoniae infection cycle in human monocytic and endothelial cells by iron, tryptophan availability and interferon gamma. Immunobiology (2010) 215:842-8. doi:10.1016/j.imbio. 2010.05.021

91. Krausse-Opatz B, Wittkop U, Gutzki FM, Schmidt C, Jürgens-Saathoff B, Meier S, et al. Free iron ions decrease indoleamine 2,3-dioxygenase expression and reduce IFNgamma-induced inhibition of Chlamydia trachomatis infection. Microb Pathog (2009) 46:289-97. doi:10.1016/j.micpath.2009.03.001

92. Weiss G, Fuchs D, Hausen A, Reibnegger G, Werner ER, Werner-Felmayer G, et al. Iron modulates interferon-gamma effects in the human myelomonocytic cell line THP-1. Exp Hematol (1992) 20:605-10.

93. Leonhardt RM, Lee SJ, Kavathas PB, Cresswell P. Severe tryptophan starvation blocks onset of conventional persistence and reduces reactivation of Chlamydia trachomatis. Infect Immun (2007) 75:5105-17. doi:10.1128/IAI. 00668-07

94. Pellegrin K, Neurauter G, Wirleitner B, Fleming AW, Peterson VM, Fuchs D. Enhanced enzymatic degradation of tryptophan by indoleamine 2,3dioxygenase contributes to the tryptophan-deficient state seen after major trauma. Shock (2005) 23:209-15.

95. Suzuki Y, Suda T, Yokomura K, Suzuki M, Fujie M, Furuhashi K, et al. Serum activity of indoleamine 2,3-dioxygenase predicts prognosis of community-acquired pneumonia. J Infect (2011) 63:215-22. doi:10.1016/j.jinf. 2011.07.003

96. Darcy CJ, Davis JS, Woodberry T, McNeil YR, Stephens DP, Yeo TW, et al. An observational cohort study of the kynurenine to tryptophan ratio in sepsis: association with impaired immune and microvascular function. PLoS One (2011) 6:e21185. doi:10.1371/journal.pone.0021185

97. Tattevin P, Monnier D, Tribut O, Dulong J, Bescher N, Mourcin F, et al. Enhanced indoleamine 2,3-dioxygenase activity in patients with severe sepsis and septic shock. J Infect Dis (2010) 201:956-66. doi:10.1086/650996

98. Huttunen R, Syrjänen J, Aittoniemi J, Oja SS, Raitala A, Laine J, et al. High activity of indoleamine 2,3 dioxygenase enzyme predicts disease severity and case fatality in bacteremic patients. Shock (2010) 33:149-54. doi:10.1097/SHK. 0b013e3181ad3195

99. Liu H, Huang L, Bradley J, Liu K, Bardhan K, Ron D, et al. GCN2-dependent metabolic stress is essential for endotoxemic cytokine induction and pathology. Mol Cell Biol (2014) 34:428-38. doi:10.1128/MCB.00946-13

100. Jung ID, Lee MG, Chang JH, Lee JS, Jeong YI, Lee CM, et al. Blockade of indoleamine 2,3-dioxygenase protects mice against lipopolysaccharideinduced endotoxin shock. J Immunol (2009) 182:3146-54. doi:10.4049/ jimmunol.0803104

101. Schefold JC, Zeden JP, Pschowski R, Hammoud B, Fotopoulou C, Hasper $\mathrm{D}$, et al. Treatment with granulocyte-macrophage colony-stimulating factor is associated with reduced indoleamine 2,3-dioxygenase activity and kynurenine pathway catabolites in patients with severe sepsis and septic shock. Scand J Infect Dis (2010) 42:164-71. doi:10.3109/00365540903405768

102. Driesen J, Popov A, Schultze JL. CD25 as an immune regulatory molecule expressed on myeloid dendritic cells. Immunobiology (2008) 213:849-58. doi:10.1016/j.imbio.2008.07.026

103. Sakai N, Kaufman S, Milstein S. Tetrahydrobiopterin is required for cytokineinduced nitric oxide production in a murine macrophage cell line (RAW 264). Mol Pharmacol (1993) 43:6-10.

104. Schoedon G, Troppmair J, Fontana A, Huber C, Curtius HC, Niederwieser A. Biosynthesis and metabolism of pterins in peripheral blood mononuclear cells and leukemia lines of man and mouse. Eur J Biochem (1987) 166:303-10. doi:10.1111/j.1432-1033.1987.tb13515.x 
105. Werner ER, Werner-Felmayer G, Fuchs D, Hausen A, Reibnegger G, Yim JJ, et al. Tetrahydrobiopterin biosynthetic activities in human macrophages, fibroblasts, THP-1, and T 24 cells. GTP-cyclohydrolase I is stimulated by interferongamma, and 6-pyruvoyl tetrahydropterin synthase and sepiapterin reductase are constitutively present. J Biol Chem (1990) 265:3189-92.

106. Thomas SR, Mohr D, Stocker R. Nitric oxide inhibits indoleamine 2,3dioxygenase activity in interferon-gamma primed mononuclear phagocytes. J Biol Chem (1994) 269:14457-64.

107. Sono M. The roles of superoxide anion and methylene blue in the reductive activation of indoleamine 2,3-dioxygenase by ascorbic acid or by xanthine oxidase-hypoxanthine. J Biol Chem (1989) 264:1616-22.

108. Hayaishi O, Hirata F, Ohnishi T, Henry JP, Rosenthal I, Katoh A. Indoleamine 2,3-dioxygenase: incorporation of $18 \mathrm{O} 2$ - and $18 \mathrm{O} 2$ into the reaction products. J Biol Chem (1977) 252:3548-50.

109. Ohnishi T, Hirata F, Hayaish O. Indoleamine 2,3-dioxygenase. Potassium superoxide as substrate. J Biol Chem (1977) 252:4643-7.
Conflict of Interest Statement: The authors declare that the research was conducted in the absence of any commercial or financial relationships that could be construed as a potential conflict of interest.

Received: 30 May 2014; paper pending published: 24 June 2014; accepted: 28 July 2014; published online: 11 August 2014.

Citation: Schmidt SV and Schultze JL (2014) New insights into IDO biology in bacterial and viral infections. Front. Immunol. 5:384. doi: 10.3389/fimmu.2014.00384

This article was submitted to Immunological Tolerance, a section of the journal Frontiers in Immunology.

Copyright (C) 2014 Schmidt and Schultze. This is an open-access article distributed under the terms of the Creative Commons Attribution License (CC BY). The use, distribution or reproduction in other forums is permitted, provided the original author(s) or licensor are credited and that the original publication in this journal is cited, in accordance with accepted academic practice. No use, distribution or reproduction is permitted which does not comply with these terms. 